\title{
Learning Heritage Language Through Serious Games in Migrant School-aged Children
}

\begin{abstract}
Shengjia Guan ${ }^{1, *}$
The University of Melbourne, Australia

*Corresponding author. Email: jillguan731114@gmail.com

ABSTRACT

Heritage language (HL), also named home language that people are used to speak from home, has advantages in children's development of cognition, academy, psychology and cultural identity. However, migrant children have been facing many challenges in maintaining their HL mainly due to lack of HL learning motivation, especially when they enroll in local schools. This study aims to examine the potential of applying serious games to improve HL learning among migrant children. This paper searches studies related to HL learning mainly in ProQuest database. Although recent studies show that serious games may be more effective in increasing children's motivation in language learning compared to the traditional approaches such as in-school classes, only two studies aim to improve HL study among school-aged children by playing serious games are retrieved. One study indicates an improvement of HL literacy skill in the children after playing the educational games, while another has no evaluation of the game's effectiveness. Therefore, the effectiveness of using serious games to promote HL learning in children are full of uncertainty so far. More serious games are needed to be developed and more studies that examining the game's effectiveness in learning HL among school-aged children should be conducted.
\end{abstract}

Keywords: Heritage language learning, migrant children, serious games, online games

\section{INTRODUCTION}

Heritage language, also known as home language and community language, commonly refers to the minority language in the society that are endangered, or the language learned at home in childhood [1, 2, 3, 4]. The HL learners tend to be more competent in using the dominant language and more likely to speak that language in daily life compared to the HL, if the learners are exposed to an environment with the dominant language that is not the HL for a long time. As a result, the proficiency of the HL may be lost or reduced among these learners as they grow up [5, 6]. In addition, with the development of globalization, the number of the immigrant family has increased rapidly in different countries. For example, nearly $30 \%$ of the Australian population were born overseas, and $21 \%$ of Australian population speak non-English language at home $[7,8]$.

Many studies show that HL maintenance benefits immigrant children's cognition development, psychology and academy [9], while HL loss would cause negative impacts on individuals, families, communities and society $[10,11]$, for instance, failure to communicate with relatives [12], unwillingness to interact with people who can speak HL [13], loss of cultural identity and sense of belongings [14], and low self-esteem [15]. According to Bartolome, the contempt for children's HL negatively affects their academic and psychological development as well [16]. Meanwhile, bilingualism could develop a balanced cultural identity [17], indicating that $\mathrm{HL}$ is a significant factor in forming powerful biculturalism [18]. Immigrant children can benefit from bilingualism and biculturalism, including strengthening inter-relationships of families and ethnic communities by generation [19], better performance in working memory based mainly on the executive process [20], and economic advantages of marketing values due to their bilingualism skills [13].

However, it is challenging to maintain HL in the first generation of immigrant children, and almost cannot be achievable beyond the third generation [21, 22]. Incomplete language acquisition is the most common theory of damaged HL learning [23]. The HL learners would be immersed into a setting of mainstream cultural language (i.e. second language) when they are 
school-aged, the input of their HL has reduced. Nevertheless, the HL learners do not fully acquire their HL through childhood [24]. Thus, these children may be proficient in oral $\mathrm{HL}$ whereas unable to read or write their HL due to a lack of HL education in their schools [25]. The environment of the dominant language and insufficient input of HL further exacerbates the attrition of HL literacy acquisition [23]. Studies from US, Australia and Canada demonstrate that many migrant parents have expectations to maintain their children's HL through family involvement (e.g. communicating with children by using HL) and community language schools (e.g. HL teaching classes and assigning HL homework) [26, 27]. The younger the bilingual children, the more fluent the bilingual [28]. However, studies show that the current interventions have not significantly improved the proficiency of children's HL mainly because the children lack motivation $[29,30,31$, 32 ]. In the past ten years, some researchers have turned attention to use serious games that have educational component in language learning for children $[3,33,34$, $35]$, since the interactive essence of games can stimulate the children's active learning [36]. This article will discuss the overview of current interventions and focus on the potential of applying games to the improvement of HL study among migrant children.

\section{BRIEF OVERVIEW OF HL LEARNING INTERVENTIONS}

\subsection{Family-involvement}

Migrant parents are essential to the HL maintenance of their children. Parental attitudes and support play a key role in HL development. Positive guides towards HL from the parents result in their children's positive view to $\mathrm{HL}[32,37,38]$. The basis of long-term academic achievement among children is firstly built by interactions with parents [39]. Although some parents have concerns that HL may disturb learning the dominant language, most parents recognize the importance of maintaining $\mathrm{HL}$ and intervening their children's HL development at home [32, 40]. For example, speaking HL at home at most time, providing bilingual or HL bookings or watching HL videos [32, $41,42]$. Despite this, many parents' actual practice is not consistent with their attitudes [32, 40]. A study that targets on Australian-Chinese parents demonstrates that some parents would unconsciously add English when speaking Chinese; the values of bilingual books or videos provided to their children are based on the western world instead of Chinese tradition, and some children show preference in English version [32]. In addition, many parents do not have enough time and energy to teach HL to their children, which further reduces children's exposure to their HL [40].

\subsection{Community language schools}

The current language schools for HL education are predominantly community-based $[4,9]$, although there is sufficient evidence indicates that setting bilingual curriculums in public schools is the best mode for HL development [43]. The community language schools can make up for migrant parents' lack of literacy training of HL for their children. Most of these schools also teach both HL and heritage culture, some even convey knowledge about history and religion, to cultivate the children's ethnic loyalty [4]. The teaching materials are commonly from the HL learners' original nationality, for instance, $80 \%$ of Chinese language schools use Chinese textbooks to convey Chinese traditional values by teaching Chinese folktales [44]. However, these schools have limited contributions to obviously promote children's HL [30, 31]. The appropriate materials designed for specific age ranges and different HL levels are lacking. The textbook that for younger children of the original nationality is hard to motivate students to learn HL $[4,9]$. Many students believe that attending these classes waste their leisure time as they have to go to classes at weekends and they cannot obtain any formal language credits $[4,45,46]$, which attenuates their motivation to learn HL as well [4]. Moreover, the mainstream school teachers of the HL students have no knowledge about these HL classes. Therefore, it is impossible to establish broad and close connections between HL students with similar interests and goals [9]. Besides, lack of well-trained language teachers, class time is too short to achieve HL proficiency, and most language schools cannot support students' literacy development are challenges to maintain HL learning [9].

\section{LEARNING HL THROUGH SERIOUS GAMES}

\subsection{Theoretical basis}

More and more children are interested in learning language through digital games, social media and other learning approaches with the rise of digital media [47]. Increasing numbers of articles have focused on how advanced technologies facilitate language study among young learners [48]. For example, Pim (2013) conducted an insightful introduction of current e-tools, interactive multimedia, digital games, apps and software. All of them improve language learning for both children and adults. Digital games are special in language development since it evokes learners' interests and motivation [49].

Motivation is the crucial factor affecting students' language learning [34]. Either family-based or language school-based HL interventions have a problem in motivating the children to learn HL. Boyd (2002) conducted a study demonstrates that learners with 
intrinsic motivation perform more persistently than those with extrinsic motivation when meeting academic challenges [50]. Serious games, also named educational games being used to stimulate and educate players to virtually achieve defined goals for educational objectives, are attractive for extrinsically motivated learners. Because the enjoyment of game results can be joint with the learning activity itself [51]. This approach converts the learner from a passive state to a proactive state to improve engagement, familiarity and intrinsic learning [52]. Chen and $\mathrm{Xu}$ (2019) indicate three main reasons why language learning games promote the players/learners' language acquisition [53]:

(1) The learners' attitude to language learning is promoted since the games provide high intrinsic motivation to them, which is essential in the environment of language acquisition.

(2) The rich texts in the games request players to use meaningful language expression to complete game tasks and activities.

(3) The game experience of interaction and immersion is helpful to reduce learner's anxiety and to encourage active learning, which may increase the use of targeted language.

This study also shows that the majority of students like playing game-based study, especially interactive-based games. The study experience is much better than traditional teaching classes, including deepen and comprehensive understanding of language learning. Similar results were demonstrated by Purushotma, Thorne and Wheatley (2009), the fascinating fictional stories integrated with text and language components, appropriate animation, attractive design of characters and avatars, effects of videos and audios, and other virtual experience of the serious games successfully stimulate learner's interaction with peers and nurture their constructional competition spirit [54]. However, Whitton (2014) holds different opinions. He points out that serious games are usually designed with specific educational results in mind, which results in games lacking meaningful interaction and limited attractiveness for players [55].

Although some researchers have observed the positive impact of games on language learning, such as DeHann, Cooke-Plagwitz, Suh, Kim and Kim and Chen and Yang, most of them aimed at foreign/second language learning or literacy development of dominant language in early childhood [56], the study targets to HL learning is limited [57, 58]. Additionally, correlating gameplay with individual or cultural identity lack attention so far [57]. Therefore, the effectiveness of HL learning games is full of uncertainty.

\subsection{Home-based games for HL study}

Eisenchlas, Schalley and Moyes conducted a pilot study in Australia to examine the literacy development of HL in Australian-Germany immigrant children by designing games for Germany study [58]. Participants consisted of 9 English-dominant children aged 5-8 with different oral levels of Germany. Five of them are in the control group (accepted test without playing games). All of the participants had enrolled in Australian schools before this study. The children self-played three German online games - Bubbles, Zoo and Handball - at home during the period of this pilot study (two to three weeks). These games are designed based on models of Germany literacy acquisition [59]. All of these games have competition components: 1) players must react in a short time to gain points after hearing the questions or description (e.g. quickly click bubbles with letters in Bubbles, quickly drag correct letters on zoo's signs in Zoo, or throw balls with correct words into the goal in Handball), 2) artificial intelligence in Zoo and Handball to compete with players. After playing the games, the researchers conducted post-evaluations for children by testing Germany proficiency levels and literacy skills, and feelings of playing the games. Parents of the children also received interviews about games' applicability and observations of the strategies used by their children when playing games.

In this study, both parents and children showed satisfaction with the games. Children especially liked the instant feedback provided during the games. The children in the game group had progressed in dictation tests, including word spelling, interference effects, free writing task, and syllable ordering task by comparing pre-and post-test results. They even wrote more words spontaneously in free writing tasks. By contrast, children in the control group performed little change in literacy level before and after the tests. The findings indicate that children's HL literacy ability can be cultivated through self-directed HL learning games, which is hopeful. However, the size of this study is too small to generalize to other communities. Also, the participants are from middle-class families, unlike refugee children, who have no experience of being interrupted schoolwork because of migration or being traumatized. Therefore, results may be different when piloting on different demographics.

It is worthwhile to mention that parents play the role of gatekeepers in children's acquisition and use of technology, for instance, choosing and buying appropriate game apps for children, setting up visit restrictions of hardware (e.g. tablets, laptops or mobile phones), and control screen time [57]. Parents' attitudes towards screen time and the ability of screening app stores used for language learning are the potential promoter for their children to develop HL's read and write skills. Parents can join in their children's game 
world and knowledge reserve [60], and to access games with higher HL-level by regarding the games as share resources [61]. In general, most parents have positive attitudes towards HL learning games [57, 62]. However, HL learning games cannot substitute interaction and communication between children and parents, despite the quality and content of the games are important [57].

\subsection{School-based games for HL study}

Revithiadou et al. (2015) developed a Computer-Assisted Language Learning (CALL) app called The 7 Keys of the Dragon (7Keys) for primaryand secondary school students in Greece whose HL is Albanian or Russian to learn these languages in class [48]. This HL curriculum adopted a blended learning model [63] - integrate class study and CALL components - to be used in a single teaching context. Participating students aged 9-13 from different backgrounds played 7Keys after morning class in school every weekday from 2011 to the end of the 2013 semester. The students had different HL oral levels, but had no or limited writing skills before the intervention. 7Keys aimed to provide teacher-student interactions without time and location limitations, make learners feel that it is an extension of class learning by keeping the existing structure of HL class and inspired students due to the game's mechanism. Furthermore, students could focus on their own language needs when playing it. The teachers could control the class and adjust the teaching materials in the game to meet students' specific needs. The teachers were responsible for managing students of their own class by 7Keys, including commenting on student's progress, answering students' questions, and marking students' performance. The administer centrally controlled the study content to ensure the new texts were correct and culturally appropriate through fostering a deeper understanding of the two nations.

7 Keys are designed to immerse learners in stories that develop alongside learners' academic skills of their HL by setting up a game-like environment with fairy-tale pictures, animations, voice, and introductory video sequences. It imitated modern games and used a reward mechanism such as gaining points in tests to show student's progress in pursuing goals. In addition, the learning materials were made up by chapters. Each chapter is based on the text contained text and a large number of quizzes (e.g. true/false, multiple-choice, fill-in-the-blanks, fill-in-the-table, crosswords) at a specific learner level. Learners could choose both the chapter and level that best suits him/her with the assistance of his/her teacher. In the learning sequences, learners choose a text of the chapter and code the language level with different colors. After reading the text, they go to the test list with different difficulty levels. The teachers then comment the test results in half screen by using their ends. A good performance could be awarded a medal.

Since the researchers aimed to enhance the students' grammatical skills and language awareness by providing a digital environment in class, they could not evaluate 7Keys' effectiveness due to the time limitation and the pilot nature when developing this app.

\section{CONCLUSION}

HL plays a key role in cultural identity and psychological and academic development among migrant children. However, HL loss would increase seriously, particularly when these children enter a school setting dominated by mainstream language. Although there are some approaches such as family involvement and community language schools to maintain children's HL, most current HL learning interventions have not significantly improved school-aged children's HL. Games as an interactive tool have been proved as an effective alternative for language study. However, applying games into HL learning for children has not been thoroughly investigated, the effectiveness of the games are uncertain [41, 57]. Only two researches related to HL learning games for immigrant children were retrieved [48, 58]. More studies needed to be conducted to verify the role of games in HL learning among children. HL learners who are different from traditional language learners actually are in needs of both mother language and foreign languages [64]. Also, it is vital to combine intrinsic motivation (motivations of learning activity itself) with extrinsic motivation (motivations of ideal game results) when developing the serious game [51].

\section{AUTHORS' CONTRIBUTIONS} Guan.

This paper is independently completed by Shengjia

\section{ACKNOWLEDGMENTS}

I acknowledge Professor Denes Szucs and Xiaoqian Zhou who contributed to the inspiration and knowledge related to language learning to this paper. I also appreciate Cuihong Wang and Jiaqiong Sun for providing advice in paper writing.

\section{REFERENCES}

[1] J. Leeman, Heritage Language Education and Identity in the United States [J] Annual Review of Applied Linguistics, vol. 35, 2015, pp. 100 - 119.

[2] G. Valdes, The teaching of heritage languages: An introduction for Slavic-teaching professionals $[\mathrm{J}]$ The Learning and Teaching of Slavic Languages and Cultures, 2000, pp. 375-403. 
[3] B. Meyer, Game-based language learning for pre-school children: a design perspective [C] Proceedings of the 6th European Conference on Games Based Learning: ECGBL, Academic Conferences Limited, 2012, p. 332.

[4] S. A. Eisenchlas, A. C. Schalley \& D. Guillemin, The Importance of Literacy in the Home Language: The View From Australia [J] SAGE Open, vol. 3, no. 4, 2013, p. 2158244013507270.

[5] G. Valdés, Bilingualism, heritage language learners, and SLA research: Opportunities lost or seized? [J] The modern language journal, vol. 89, no. 3, 2005, pp. 410-426.

[6] S. Montrul, Current issues in heritage language acquisition $[\mathrm{J}]$ Annual Review of Applied Linguistics, vol. 30, 2010, p. 3.

[7] Australian Bureau of Statistics, Migration Australia. 2021.

https://www.abs.gov.au/statistics/people/population /migration-australia/latest-release

[8] Census of Population and Housing: Reflecting Australia - Stories from the Census, 2016. 2017. https://www.abs.gov.au/ausstats/abs@.nsf/Lookup/ by Subject/2071.0 2016 Main Features Cultural Diversity Data Summary 30

[9] J. S. Lee \& W. E. Wright, The Rediscovery of Heritage and Community Language Education in the United States [J] Review of Research in Education, vol. 38, no. 1, 2014, pp. 137-165.

[10] L. W. Fillmore, Loss of Family Languages: Should Educators Be Concerned? [J] Theory into Practice, vol. 39 , no. 4 , 2000, pp. 203-210.

[11] L. Tse, Resisting and Reversing Language Shift: Heritage-Language Resilience among U.S. Native Biliterates [J] Harvard Educational Review, vol. 71, 2001, pp. 676-709.

[12] O. Nesteruk \& L. Marks, Grandparents across the ocean: Eastern European immigrants' struggle to maintain intergenerational relationships [J] Journal of Comparative Family Studies, vol. 40, no. 1, 2009, pp. 77-75.

[13] G. Cho, The role of heritage language in social interactions and relationships: Reflections from a language minority group [J] Bilingual Research Journal, vol. 24, no. 4, 2000, pp. 369-384.

[14] Y. Wang, Language, Parents' Involvement, and Social Justice: The Fight for Maintaining Minority Home Language: A Chinese-Language Case Study [J] Multicultural Education, vol. 16, no. 4, 2009, pp. 13-18.
[15] L. W. Fillmore, When learning a second language means losing the first [J] Early Childhood Research Quarterly, vol. 6, no. 3, 1991, pp. 323-346.

[16] L. I. Bartolomé, Authentic cariño and respect in minority education: The political and ideological dimensions of love $[\mathrm{J}]$ The International Journal of Critical Pedagogy, vol. 1, no. 1, 2008.

[17] A. Portes \& L. Hao, The price of uniformity: Language, family and personality adjustment in the immigrant second generation $[\mathrm{J}]$ Ethnic and racial studies, vol. 25, no. 6, 2002, pp. 889-912.

[18] J. Zhang, Mandarin maintenance among immigrant children from the People's Republic of China: an examination of individual networks of linguistic contact $[\mathrm{J}]$ Language, Culture and Curriculum, vol. 22, no. 3, 2009, pp. 195-213.

[19] O. Nesteruk, Heritage language maintenance and loss among the children of Eastern European immigrants in the USA [J] Journal of Multilingual and Multicultural Development, vol. 31, no. 3, 2010, pp. 271-286.

[20] E. Bialystok, F. I. Craik, R. Klein \& M. Viswanathan, Bilingualism, aging, and cognitive control: evidence from the Simon task [J] Psychology and aging, vol. 19, no. 2, 2004, p. 290.

[21] R. Rumbaut, “Chapter 1. A Language Graveyard? The Evolution of Language Competencies, Preferences and Use Among Young Adult Children of Immigrants", The Education of Language Minority Immigrants in the United States, 2009.

[22] C. Veltman, Language Shift in the United States, De Gruyter Mouton, 2014.

[23] S. Montrul \& M. Bowles, Back to basics: Incomplete knowledge of Differential Object Marking in Spanish heritage speakers [J] Bilingualism, vol. 12, no. 3, 2009, p. 363.

[24] P. Guijarro-Fuentes \& K. Schmitz, The nature and nurture of heritage language acquisition $[\mathrm{J}]$ Lingua, vol. 164, no. B, 2015, pp. 239-250.

[25] S. Montrul, R. Foote \& S. Perpiñán, Gender agreement in adult second language learners and Spanish heritage speakers: The effects of age and context of acquisition [J] Language Learning, vol. 58, no. 3, 2008, pp. 503-553.

[26] J. Reaser, Terrence G. Wiley, Literacy and language diversity in the United States [J] Language in Society, vol. 36, no. 5, 2007, pp. 781-785.

[27] W. Yang, Chinese Language Maintenance: A Study of Chinese-American Parental Perceptions 
and Activities [J] Journal of Chinese Overseas, vol. 3, 2007, pp. 220-238.

[28] S. Montrul, Incomplete acquisition in bilingualism [J] Re-examining the age factor, 2008.

[29] J. S. Lee, The Korean Language in America: The Role of Cultural Identity in Heritage Language Learning [J] Language, Culture and Curriculum, vol. 15, no. 2, 2002, pp. 117-133.

[30] M. Zhou \& S. S. Kim, Community Forces, Social Capital, and Educational Achievement: The Case of Supplementary Education in the Chinese and Korean Immigrant Communities [J] Harvard Educational Review, vol. 76, no. 1, 2006, pp. 1-29.

[31] B.-K. You, "Korean heritage language schools in the United States (Heritage Brief)", Center for Applied Linguistics, Washington, DC, 2011.

[32] J. Hu, J. Torr \& P. Whiteman, Australian Chinese parents' language attitudes and practices relating to their children's bilingual development prior to school [J] Journal of Early Childhood Research, vol. 12, no. 2, 2014, pp. 139-153.

[33] D. N. Karagiorgas \& S. Niemann, Gamification and Game-Based Learning $[\mathrm{J}]$ Journal of Educational Technology Systems, vol. 45, no. 4, 2017, pp. 499-519.

[34] J.-C. Hong, M.-Y. Hwang, K.-H. Tai \& P.-H. Lin, Intrinsic motivation of Chinese learning in predicting online learning self-efficacy and flow experience relevant to students' learning progress [J] Computer Assisted Language Learning, vol. 30, no. 6, 2017, pp. 552-574.

[35] B. H. Sørensen \& B. Meyer, Serious Games in language learning and teaching-a theoretical perspective [C] DiGRA Conference, 2007, pp. 559-566.

[36] P. Wouters, C. Van Nimwegen, H. Van Oostendorp \& E. D. Van Der Spek, A meta-analysis of the cognitive and motivational effects of serious games [J] Journal of educational psychology, vol. 105, no. 2, 2013, p. 249.

[37] J. A. Fishman, Reversing language shift: Theoretical and empirical foundations of assistance to threatened languages, vol. 76, Multilingual matters, 1991.

[38] M. Tannenbaum \& P. Howie, The association between language maintenance and family relations: Chinese immigrant children in Australia [J] Journal of Multilingual and Multicultural Development, vol. 23, no. 5, 2002, pp. 408-424.
[39] E. A. Sloat, N. L. Letourneau, J. R. Joschko, E. A. Schryer \& J. E. Colpitts, Parent-mediated reading interventions with children up to four years old: A systematic review [J] Issues in comprehensive pediatric nursing, vol. 38, no. 1, 2015, pp. 39-56.

[40] F. Liang, Parental Perceptions toward and Practices of Heritage Language Maintenance: Focusing on the United States and Canada [J] Online Submission, vol. 12, no. 2, 2018, pp. 65-86.

[41] W. E. Yang, Chinese language maintenance: A study of Chinese-American parental perceptions and activities $[\mathrm{J}]$ Journal of Chinese Overseas, vol. 3, no. 2, 2007, pp. 220-238.

[42] D. Zhang, Home language maintenance among second generation Chinese American children [J] Working Papers in Educational Linguistics (WPEL), vol. 19, no. 2, 2004, p. 2.

[43] M. Swain, S. Lapkin, N. Rowen \& D. Hart, The role of mother tongue literacy in third language learning [J] Language, Culture and Curriculum, vol. 3, no. 1, 1990, pp. 65-81.

[44] X. Wang, A View from Within: A Case Study of Chinese Heritage Community Language Schools in the United States, ERIC, 1996.

[45] B.-K. You, Developing in Two Languages: Korean Children in America [J] International Multilingual Research Journal, vol. 1, no. 1, 2007, pp. 45-55.

[46] R. S. Lao \& J. S. Lee, Heritage language maintenance and use among 1.5 generation Khmer college students $[\mathrm{J}]$ Journal of Southeast Asian American Education and Advancement, vol. 4, no. 1, 2009 , p. 3.

[47] J. P. Gee \& E. R. Hayes, Language and learning in the digital age, Routledge, 2011.

[48] A. Revithiadou, V. Kourtis-Kazoullis, M. Soukalopoulou, K. Konstantoudakis \& C. Zarras, Developing CALL for heritage languages: The 7 Keys of the Dragon [J] The EuroCALL Review, vol. 23, no. 2, 2015, pp. 38-57.

[49] C. Pim \& G. Motteram, Emerging technologies, emerging minds: digital innovations within the primary sector [C] 2013.

[50] F. B. Boyd, Motivation to continue: Enhancing literacy learning for struggling readers and writers [J] Reading \& Writing Quarterly, vol. 18, no. 3, 2002, pp. 257-277.

[51] D. Drummond, A. Hadchouel \& A. Tesnière, Serious games for health: three steps forwards [J] Advances in Simulation, vol. 2, no. 1, 2017, pp. $1-8$. 
[52] A. Ypsilanti, A. B. Vivas, T. Räisänen, M. Viitala, T. Ijäs \& D. Ropes, Are serious video games something more than a game? A review on the effectiveness of serious games to facilitate intergenerational learning $[\mathrm{J}]$ Education and Information Technologies, vol. 19, no. 3, 2014, pp. 515-529.

[53] H.-J. H. Chen \& H.-L. Hsu, The impact of a serious game on vocabulary and content learning [J] Computer Assisted Language Learning, vol. 33, no. 7, 2020, pp. 811-832.

[54] R. Purushotma, S. L. Thorne \& J. Wheatley, 10 key principles for designing video games for foreign language learning, 2009.

[55] N. Whitton, Digital games and learning: Research and theory, Routledge, 2014.

[56] J. W. DeHaan, Acquisition of Japanese as a foreign language through a baseball video game $[\mathrm{J}]$ Foreign Language Annals, vol. 38, no. 2, 2005, pp. 278-282.

[57] S. Little, 'Is there an app for that?' Exploring games and apps among heritage language families [J] Journal of Multilingual and Multicultural Development, vol. 40, no. 3, 2019, pp. 218-229.

[58] S. A. Eisenchlas, A. C. Schalley \& G. Moyes, Play to learn: self-directed home language literacy acquisition through online games $[\mathrm{J}]$ International Journal of Bilingual Education and Bilingualism, vol. 19 , no. 2, 2016, pp. 136-152.

[59] G. Spitta, Kinder schreiben eigene Texte: Klasse 1 und 2 [J] Bielefeld. Cornelsen, 1983.

[60] N. González, L. C. Moll \& C. Amanti, Funds of knowledge: Theorizing practices in households, communities, and classrooms, Routledge, 2006.

[61] R. M. Ryan \& E. L. Deci, Self-determination theory: Basic psychological needs in motivation, development, and wellness, Guilford Publications 2017.

[62] T. Szecsi \& J. Szilagyi, Immigrant Hungarian families' perceptions of new media technologies in the transmission of heritage language and culture [J] Language, Culture and Curriculum, vol. 25, no. 3, 2012, pp. 265-281.

[63] F. Mishan, Demystifying blended learning [J] Developing materials for language teaching, 2013, pp. 207-223.

[64] C. Baker, Foundations of bilingual education and bilingualism, Multilingual matters, 2011. 